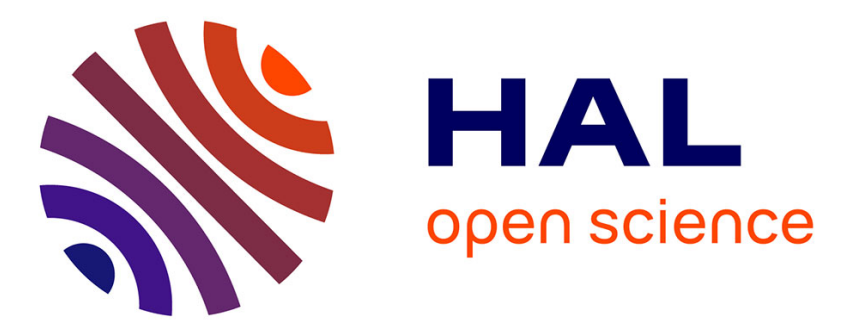

\title{
Large-scale dexterous haptic interaction with virtual mock-ups: Methodology and human performance
}

\author{
Damien Chamaret, Paul Richard, Sehat Ullah
}

\section{To cite this version:}

Damien Chamaret, Paul Richard, Sehat Ullah. Large-scale dexterous haptic interaction with virtual mock-ups: Methodology and human performance. 6th International Conference on Informatics in Control, Automation and Robotics (ICINCO 2009), Jul 2009, Milan, Italy. pp.453-456. hal-00869611

\section{HAL Id: hal-00869611 \\ https://hal.science/hal-00869611}

Submitted on 10 Mar 2014

HAL is a multi-disciplinary open access archive for the deposit and dissemination of scientific research documents, whether they are published or not. The documents may come from teaching and research institutions in France or abroad, or from public or private research centers.
L'archive ouverte pluridisciplinaire HAL, est destinée au dépôt et à la diffusion de documents scientifiques de niveau recherche, publiés ou non, émanant des établissements d'enseignement et de recherche français ou étrangers, des laboratoires publics ou privés. 


\title{
LARGE-SCALE DEXTEROUS HAPTIC INTERACTION WITH VIRTUAL MOCK-UPS Methodology and Human Performance
}

\author{
Damien Chamaret, Paul Richard \\ LISA Laboratory, University of Angers, 62 avenue Notre Dame Du Lac, Angers, France \\ \{damien.chamaret, paul.richard\}@univ-angers.fr \\ Sehat Ullah \\ IBISC Laboratory, University of Evry, 40 rue du Pelvoux, Evry, France \\ sehat.ullah@ibisc.univ-evry.fr
}

\begin{abstract}
Keywords: Virtual Environment, Virtual Mock-up, Large-scale, Haptic Interaction, Human Performance.
Abstract: We present a methodology for both the efficient integration and dexterous manipulation of CAD models in a physical-based virtual reality simulation. The user interacts with a virtual car mock-up using a stringbased haptic interface that provides force sensation in a large workspace. A prop is used to provide grasp feedback. A mocap system is used to track user's hand and head movements. In addition a 5DT data-glove is used to measure finger flexion. Twelve volunteer participants were instructed to remove a lamp of the virtual mock-up under different conditions. Results revealed that haptic feedback was better than additional visual feedback in terms of task completion time and collision frequency.
\end{abstract}

\section{INTRODUCTION}

Nowadays, Car manufacturers use Computer Aided Design (CAD) to reduce costs, time-to-market and to increase the overall quality of products. In this context, physical mock-ups are replaced by virtual mock-ups for accessibility testing, assembly simulations, operation training and so on. In such simulations, sensory feedback must be provided in an intuitive and comprehensible way. Therefore, it is of great importance to investigate the factors related to information presentation modalities that affect human performance. This paper presents a methodology for both the efficient integration and dexterous manipulation of CAD models in a physical-based virtual reality simulation. The user interacts with a virtual car mock-up by using a string-based haptic interface that provides force sensation in a large workspace. An experimental study was carried out to validate the proposed methodology and evaluate the effect of sensory feedback on operator's performance. Twelve participants were instructed to remove a car's lamp from a virtual mock-up. Three experimental conditions were tested concerning sensory feedback associated with collisions with the virtual mock-up: (1) no-feedback (only graphics), (2) additional visual feedback (colour) and (3) haptic feedback. Section 2 describes the CAD-to-VR methodology. Section 3 presents the virtual environment (VE) that allows large-scale haptic interaction with the virtual car mock-up. In section 4, the experimental study and the results are presented. The paper ends by a conclusion and gives some tracks for future work.

\section{CAD-TO-VR METHODOLOGY}

The proposed CAD-to-VR methodology involves different steps (illustrated in Figure 1a), such as model simplification (1), model integration (2-3). The graphical model is used for visual display of the virtual mock-up (4), while the physical one is used for both tactile and kinaesthetic feedback (5-6). Our methodology for model simplification allows to decrease the number of polygons of the CAD models while keeping the same level of visual quality. Model integration allows to obtain both graphical and physical models of CAD data. Physical models are built using PhysX engine (www.nvidia.com). 


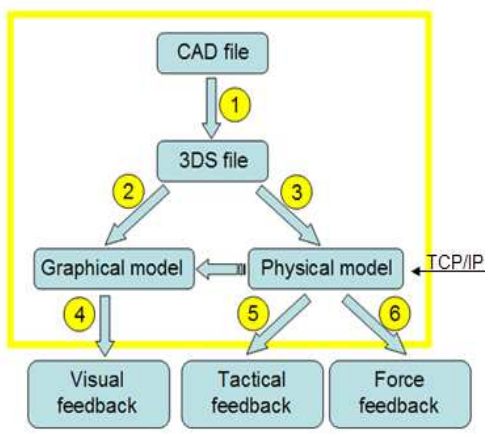

(a)

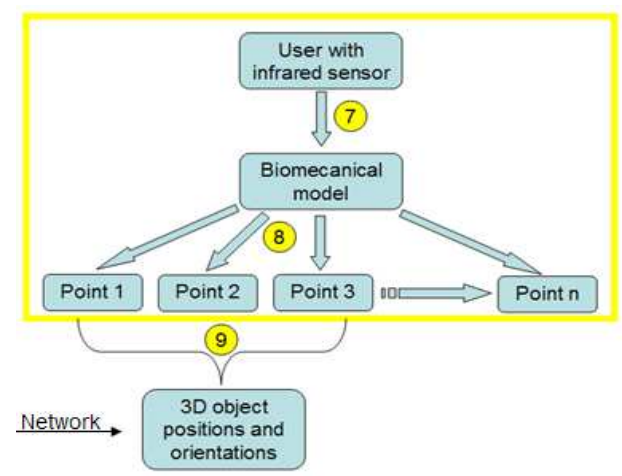

(b)

Figure 1: Schematic of the CAD-to-VR methodology (a) and human interaction using the mocap system (b).

\section{VIRTUAL ENVIRONMENT}

Our methodology also allows the integration of both the graphical and physical models of users (Figure 1b). A biomechanical model is used for the animation of operator's hand and arm (7). In order to get accurate position and orientation tracking of the user, an infrared camera-based motion capture system is used. Six reflected markers are placed on the operator's body (8): three markers on the data-glove to assess hand position and orientation (9), one marker on a cap worn by the operator for head tracking, and two markers on the operator's arm.

The large-scale VE provides force feedback using the SPIDAR system (Space Interface Device for Artificial Reality) (Ishii and Sato, 1994). Stereoscopic images are displayed on a rearprojected large screen $(2 \mathrm{~m} \times 2.5 \mathrm{~m})$ and are viewed using polarized glasses. The SPIDAR system uses a SH4 controller from the Cyverse (Japan). In order to provide force feedback to both hands, a total of 8 motors are placed on the corners of a cubic frame surrounding the user. In order to provide haptic grasping feedback to the operator, a prop (see Figure 2) was used (Chamaret et al., 2008).

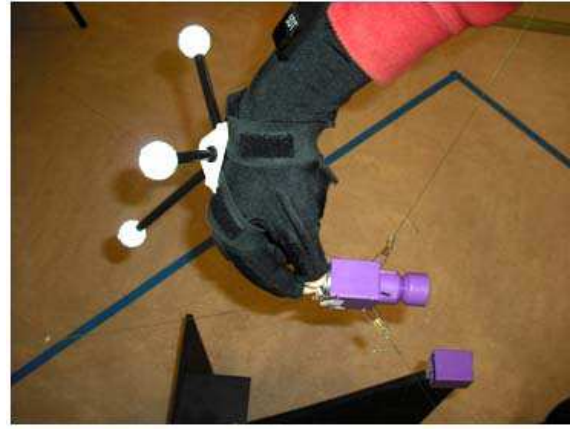

Figure 2: The prop (real car lamp inside a plastic cap) used for grasping feedback.

Poor grasp of the prop or a bad calibration due to unexpected movements may cause problems of feedback coherency between grasping (prop) and simulated forces (SPIDAR). To avoid these problems, three zones were defined: (a) a free zone where the user can freely moves his/her hand (hand position/orientation and fingers flexion) using a 5DT data glove, (b) an assistance zone $\left(\mathrm{d}_{1}=10 \mathrm{~cm}\right.$ from the virtual lamp) where the user is no more able to change fingers flexion, and (c) a grasping zone $\left(\mathrm{d}_{2}=\right.$ $5 \mathrm{~mm}$ from the virtual lamp) where the grasping gesture is realized (Figure 3):

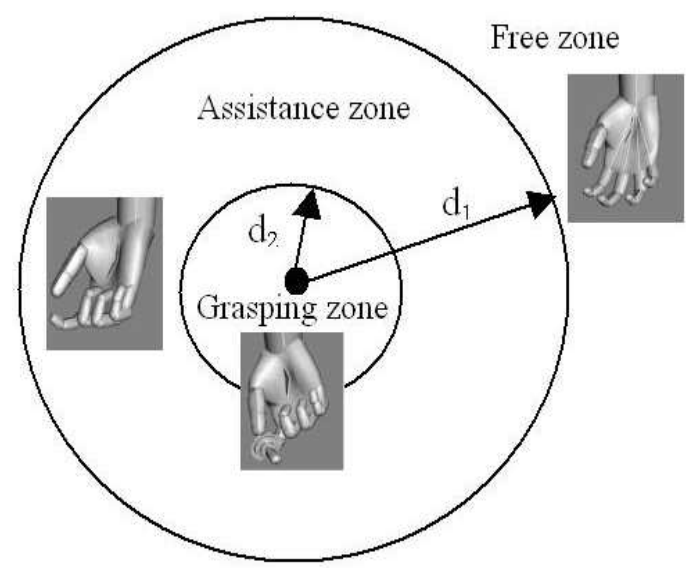

Figure 3: Illustration of the three zones used for the grasping simulation and assistance.

\section{EXPERIMENTAL STUDY}

The aim of this experiment is twofold: (1) validate the proposed CAD-to-VR methodology including operator's biomechanical model integration, and (2) investigate the effect of haptic and visual feedback on operator performance in a task involving extraction and replacement of a car's lamp in a virtual car mock-up. 


\subsection{Experimental Set-up}

The experimental set-up is illustrated in Figure 4. The user interaction with the virtual mock-up using the camera-based mocap system. Global force feedback is provided using the SPIDAR system. Local (grasp) feedback is achieved using the prop.

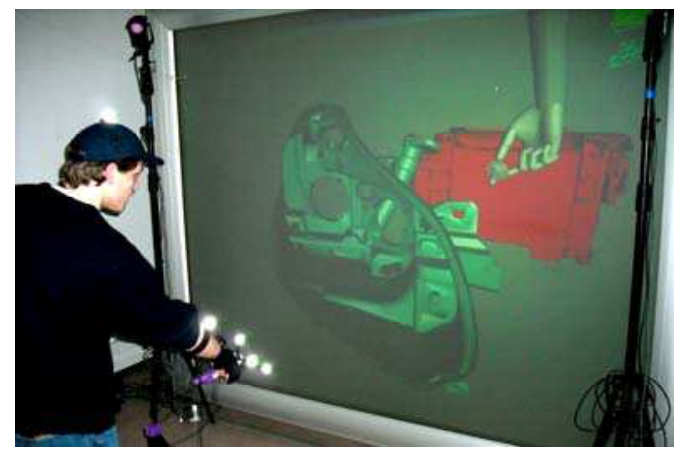

Figure 4: Illustration of a user performing the task.

\subsection{Procedure}

Twelve volunteer students participated in the experiment. They were naives in the use of virtual reality technique. Each participant had to perform the maintenance task in the following conditions:

- C1: no additional feedback (only graphics);

- C2: additional visual feedback (colour);

- C3: haptic feedback (from SPIDAR).

The task has to be repeated three times for each condition. Conditions were presented in different order to avoid any training transfer. Participants were in front of a large rear-projected screen at a distance of approximately 1.5 meter. They worn a 5DT data glove equipped with three reflective balls (Figure 2). In order to get acquainted with the system each participant performed a pre-trial of the task in $\mathrm{C} 1$ condition.

\subsection{Data Collection}

The following data were collected during the experiment for each single trial:

- $\quad$ task completion time

- number of collisions

\subsection{Results}

Results were analysed through ANOVA. We examine the effect sensory feedback on (a) task completion time and (b) collision time. Then, we look into the learning process associated with the different sensory feedback.

\subsubsection{Task Completion Time}

Results, illustrated in Figure 5, revealed that sensory feedback has a significant effect on task completion time: $\quad(\mathrm{F}(2,11)=14.08 ; \quad \mathrm{p}<0.005) . \quad$ A statistical difference between conditions $\mathrm{C} 1, \mathrm{C} 2$ and $\mathrm{C} 3$ was observed. In $\mathrm{C} 1$ condition the average completion time was $30.34 \mathrm{sec}(\mathrm{STD}=3.1)$. Average completion time was $26.45 \mathrm{sec}(\mathrm{STD}=1.8)$ for $\mathrm{C} 2$ (additional visual feedback) and $22.24 \mathrm{sec}(\mathrm{STD}=3.4)$ for $\mathrm{C} 3$ (haptic feedback). Thus visual and haptic feedbacks allow increasing performance, as compared with the open-loop case (no additional feedback), by $12.8 \%$ and $16 \%$ respectively. Haptic feedback increase performance by $15.6 \%$ as compared to additional visual feedback. However, participants' performance was more disparate.

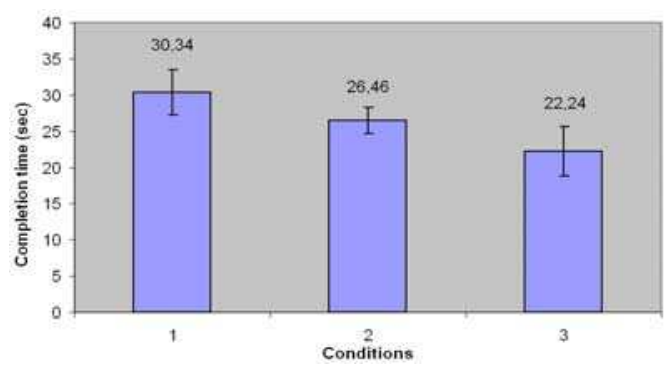

Figure 5: Completion time versus conditions.

\subsubsection{Number of Collisions}

Results, illustrated in Figure 6, revealed that sensory feedback has a significant effect on the number of collisions: $(\mathrm{F}(2,11)=63.70 ; \mathrm{p}<0.005)$. As previously, a statistical difference between $\mathrm{C} 1, \mathrm{C} 2$ and $\mathrm{C} 3$ conditions was observed. In $\mathrm{C} 1$ the average number of collisions was $6.64(\mathrm{STD}=0.58)$. The average number of collisions was $4.83 \mathrm{sec}(\mathrm{STD}=0.15)$ for $\mathrm{C} 2$ and $4.05(\mathrm{STD}=0.8)$ for $\mathrm{C} 3$. Thus visual and haptic feedbacks led to a significant reduction of the number of collisions as compared to the open-loop case, by $27.3 \%$ and $39.0 \%$ respectively. Haptic feedback increase performance by $16.2 \%$ as compared with additional visual feedback. As for task completion time, participants' performance was more disparate in condition $\mathrm{C} 3$.

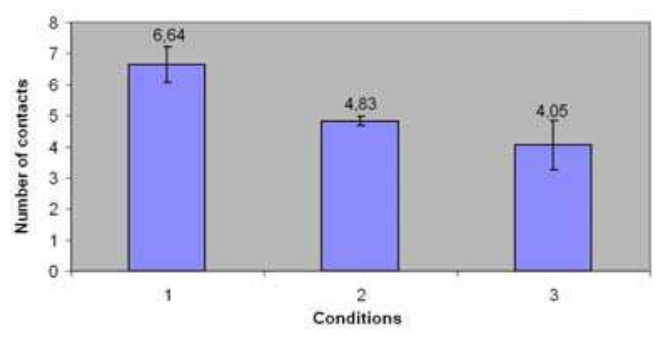

Figure 6: Number of collisions versus conditions. 


\subsubsection{Learning Process}

The learning process is defined here by the improvement of participant performance associated with task repetitions. We analysed the learning process associated with both task completion time and number of collisions. Although each participant repeated the task three times only, a learning process was observed for all conditions (Figure 7, 8, and 9).

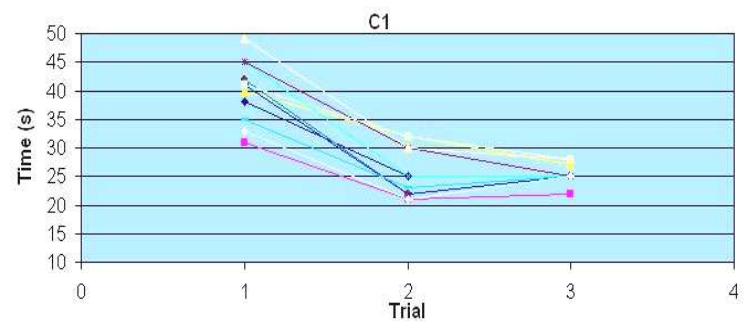

Figure 7: Learning process associated with condition 1.

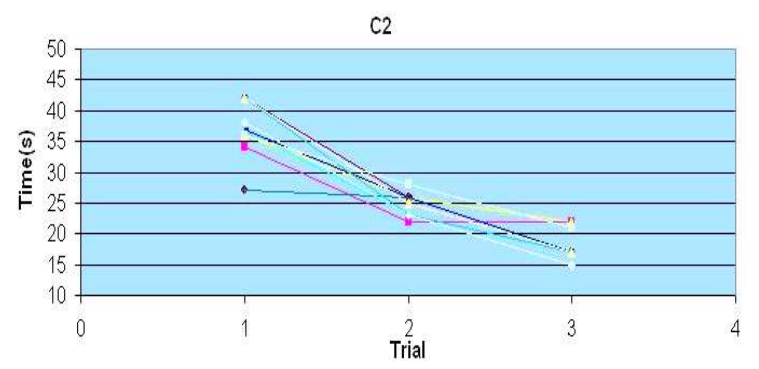

Figure 8: Learning process associated with condition 2.

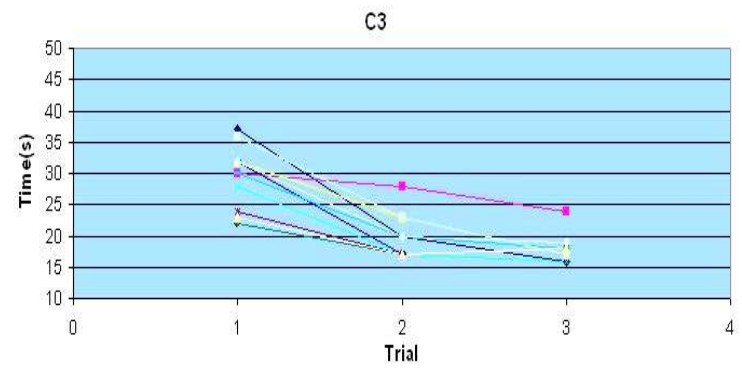

Figure 9: Learning process associated with condition 3.

Average task completion time was $40.2 \mathrm{sec}$ at the first trial and $25.4 \mathrm{sec}$ at the last trial for condition $\mathrm{C} 1,36.7 \mathrm{sec}$ at the first trial and $18.1 \mathrm{sec}$ at the last trial for condition $\mathrm{C} 2$, and $29.2 \mathrm{sec}$ at the first trial and $17.9 \mathrm{sec}$ at the last trial for condition C3. This results in a performance improvement of about $37 \%$, $50 \%$, and $48 \%$ for conditions $\mathrm{C} 1, \mathrm{C} 2$ and $\mathrm{C} 3$ respectively.

Concerning the number of collisions, we observed a poor learning process for each condition. This result is not very surprising for $\mathrm{C} 1$ condition since no feedback was displayed for collisions. In the C3 condition, participants were good at the first trial.
This shows that the haptic interface is user-friendly and efficient. The poor learning process associated with $\mathrm{C} 2$ condition may be explained by the lack of spatial information as is it the case with force feedback (sensation of force direction during collision).

\section{CONCLUSIONS}

This paper presented a methodology for both the integration and dexterous manipulation of CAD models with biomechanical model in a physicalbased virtual reality simulation. The user interacts with a virtual car mock-up using a string-based haptic interface that provides force sensation in a large workspace. Twelve participants were instructed to remove a lamp of the virtual mock-up under different conditions. Results revealed that haptic feedback was better than additional visual feedback to reduce both task completion time and collision frequency. In the near future we plan to integrate haptic guides in order to assist the users to reach and grasp the cars lamps in a more efficient way.

\section{REFERENCES}

Ishii M., Sato M., 1994. A 3d Spacial interface Device using Tensed Strings. Presence, 3(1).

Chamaret D. Richard P. Ferrier J.L., 2008. From CAD Model to Human-Scale Multimodal Interation with Virtual Mockup: An Automotive Application. $5^{\text {th }}$ International Conference on Informatics in Control, Automation and Robotics (ICINCO 2008) Madeira, Portugal. 